\title{
iER日MF
}

\section{Project Manager Competencies in Multicultural Environment}

\author{
Boryana Bogoeva \\ University of National and World Economy, Sofia, Bulgaria
}

\begin{abstract}
The purpose of this paper is to present manager competencies as a key factor for project management, as well as the belief that classical managerial practices and models focusing on traditional management are irrelevant in the contemporary international conditions. This is called for by the progressively growing number of projects managed by organisations in a multicultural environment. In today's business world, project management requires new thinking and managerial skills, as well as often overcoming existing stereotypes, values beliefs and norms, established as a result of the mainstream dimensions of the cultural environment undoubtedly of paramount importance for project management in multicultural environment too. That has led to a change in the skills project managers must have. In this respect, we are of the opinion that the research of cultural aspects in view of improving the project management toolbox is a particularly timely and important task. The theoretical contribution of this paper is the presented competency model, containing the necessary set of competencies needed by project managers in order to be able to manage in a multicultural environment based on cultural diversity diagnostics and multicultural project team functioning. The impact of the elements and the factors of a multicultural environment on project management are a not completely developed scientific area in project management. It is of paramount importance for the management practices to extrapolate ways for using the strengths of project management in a multicultural environment through some relevant knowledge, skills and competencies purposefully developed for and by project managers.
\end{abstract}

Keywords: project management, multicultural environment, competencies, culture.

\section{Introduction}

Over the past couple of decades, there was an exceptionally high increase of the use of project management as means for the organisations to attain their goals. And, if in the past the majority of the projects had been external to the organisation - building a new skyscraper, launching an advertising campaign - now the growing implementation of projects is mainly in the area of projects internal to the organisation: new product development, process upgrade, improvement of services rendered to customers. 


\section{iEREMF}

According to the Project Management Institute: "A project is a temporary endeavor undertaken to create a unique product, service or result". (PMBOK, 2000).

A multicultural project is a project where the members come from various national or ethnic backgrounds (Mäkilouko, 2004). On its part, multicultural management "involves a) procedures and policies related to the management of working groups of different cultural origin and $b$ ) mitigation of the impact of cultural differences when performing leadership tasks"(Søderberg \& Holden, 2002). Marchewka (2014) defines multicultural projects as "international or domestic projects where organizations attempt to diversify their workforce". Harzing (2001) adds, that "the greater the cultural distance between the home and the host country the greater the problems with adaptation". This is the case because the multicultural environment is characterized by exceptional dynamics and turbulences.

Cultural differences may have positive, as well as negative impact on the projects (Chevrier, 2003). The purpose of this study is to reveal the complexity behind the impact that cultural differences create in multicultural projects and to devise a model of the competencies needed by a project manager to lead in a multicultural environment. This is naturally related to the formation of a complex of factors - e.g. acquisition of organizational knowledge, effective communications, development of HR with professional competences - that affect the effectiveness of project management (Alexandrova, 2018).

PMBOK points out that "multicultural competency becomes critical for the project manager" (PMBOK, 2013). In order for a project manager to be multicultural, they have to have interpersonal skills and be adequate to the global business environment.

Multicultural project management can be successful through effective intercultural communication and consciousness, cultural sensitivity, focus on the achievements, team work and cooperation (Alexandrova, 2016). Although cultural influence is invisible, it is still noticeable. So is the fact that there is no universal cultural management. The dynamics of each project make it impossible.

The assumption that all people from one nation and all managers and employees in an organization share the same cultural values leads to ignorance towards the social differences, the diversity and the relations of power between peoples and organizations (Søderberg \& Holden, 2002). At a first glance, national borders are a good synonym for a given culture. Such framing of the notion, however, is somewhat incorrect since there is no nation that is so pure that all its members share the same prevailing point of view.

The goal of the paper is to present selected results form an empirical survey among project management professionals with a focus on the specific competencies of project managers in multicultural project-oriented organisations. The findings indicate explicitly that there is a need of detailed research to determine the basic elements and competencies of a project manager that have an impact on the implementation of a project in a multicultural environment. 


\section{iEREMF}

\subsection{The Project Manager's Role}

Currently, in project management more and more emphasis is given to behavioral aspects and managerial skills of the project managers. They themselves are faced with great challenges due to growing global competition and greater complexity of project organizations.

The leader of a project / the project manager is the one who integrates and coordinates all activities and directs them towards the successful completion of the project. They lead the project team so that it meets the goals and expectations of the stakeholders. Some of the qualities they have to have are:

- Ability to select and develop a team;

- Leadership and managerial skills;

- Ability to solve problems and make decisions;

- Ability to integrate the interested participants / parties to the project;

- Technical skills and competencies;

- Ability to negotiate;

- Ability to manage in a constantly changing environment.

The main task of a project manager is to work with people and to create a working environment based on a set of virtues (ethics, respect and confidence for the others, openness, courage, responsible use and sharing of power; Kloppenborg \& Petrick, 1999), contributing to the implementation of the project. He or she is expected to have a certain set of knowledge, skills and technical expertise in order to provide adequate leadership to his or her project team as well as an environment of established values and norms of behavior. In order to perform this uneasy task, the project manager uses communication more than any other skill in the process of project management. This is confirmed also by Carvalho (2014), who emphasizes the importance of the soft skills to a project manager and in particular the ones related to exchange of information. Communication itself is a vital element of management and open, pro-active and fair interactive communication is a prerequisite for avoiding conflict.

Moreover, a project manager is faced with yet another important challenge - the cultural diversity of the project teams.

Bearing in mind that in a multicultural project various human resources come together temporarily and perform various activities for achieving a unique set of goals, it is necessary for the members of such type of projects to understand the cultural differences and their nature.

When the project team is multicultural, it is likely that not all members comprehend in the same way the thoughts, actions and beliefs of the project manager. Very often, the project manager himself or herself is subject to analysis in the multicultural studies. 


\section{iEREMF}

Demonstrating the strong link between the culture and the style of management, applied by the leader, a greater emphasis has been given to the competency of the project manager in recent years (Eberlein 2008; Muller \& Turner 2010; Picker \& Leker 2009).

\section{Methods}

In view of the necessity to research the competencies project managers need for managing projects in multicultural environments, a study was carried out among experts with significant experience in project management.

The main stages of the study were:

Pilot study formulation

$>$ Methods for the sample (selection of units of observation);

$>$ Methods for registration (providing data);

$>$ Methods for analysis (data analysis);

$>$ Extrapolation of basic competencies necessary for a project manager for managing projects in multicultural environment.

For the purpose of the study, an author's toolbox was developed - a questionnaire. The sample of respondents (units for observation) was formed in accordance with the targeted selection method, i.e. the respondents had significant experience in project management.

In the period $03.2018-12.2018,112$ experts involved in project management participated in the study on the Surveymonkey platform. The first part of the questionnaire was questions regarding personal characteristics of the respondents. The respondents were not asked to provide any personal information that may reveal their identity, which gives us grounds to assume that the opinion and assessments shared are true and objective.

The starting point for the study was the lack of useful tips and practices regarding the question how project managers should deal with team members representing different cultures. The study demonstrates clearly the categorical opinion of all respondents for the need of multicultural teams in the organisation. More often than not, this complex task is performed by the project managers, whose aim it is to develop and manage such a team. In order to achieve it, we singled out the main elements, which the experts deemed key in a multicultural environment, namely:

- Effective communication - open and fair communication builds confidence and reduces conflict between project members;

- Conscious attitude towards the needs of the team - understanding, recognition and respect for cultural differences minimize misunderstandings and improve communication capacity;

- Adjustment - adaptation of processes, searching for alternative approaches based on the project environment, the culture and the needs of all stakeholders are part of the tasks of the project manager. We found it important for the style of the project 
manager to be adapted effectively to the different stages / conditions of the project, among the respondents too;

- Teamwork - the members of a multicultural project team have varied experience and rich professional expertise. The development of such a team leads to creating a dynamic culture based on shared values, team spirit and cooperation.

\section{Results}

112 respondents took part in this study, 27 from Bulgaria and 84 from other countries. One of the respondents did not indicate their nationality. The respondents from other countries were predominantly certified project managers (PMP - Project Management Professional) in the area of IT industry, food industry, financial and consultancy services, as well as persons working in education. A number of individual characteristics were given by each respondent (demographic and professional).

Table 1: Respondents Demographics

\begin{tabular}{|l|c|c|}
\hline \multicolumn{1}{|c|}{ Age } & In percentage & Number \\
\cline { 2 - 4 } Below 30 years & $10.71 \%$ & 12 \\
\hline $31-40$ & $43.75 \%$ & 49 \\
\hline $41-50$ & $18.75 \%$ & 21 \\
\hline $51-60$ & $16.07 \%$ & 18 \\
\hline Above 60 years old & $10.71 \%$ & 12 \\
\hline Total & $\mathbf{1 0 0 \%}$ & $\mathbf{1 1 2}$ \\
\hline Gender Distribution & & 74 \\
\hline Men & $66.07 \%$ & 38 \\
\hline Women & $33.93 \%$ & $\mathbf{1 1 2}$ \\
\hline
\end{tabular}

Source: Image by the Author

An important characteristic in view of the subject and the purpose of the survey was respondent's nationality (Table 2). One of the respondents did not provide information about his nationality. 


\section{i[CREMF}

Table 2: Respondents' Nationality

\begin{tabular}{|l|c|l|c|l|c|}
\hline \multicolumn{1}{|c|}{ Nationality } & Number & Nationality & Number & Nationality & Number \\
\hline USA & 3 & Philippines & 1 & Poland & 5 \\
\hline Argentina & 1 & Ethiopia & 1 & Romania & 1 \\
\hline Britain- Australian & 1 & Germany & 3 & Russia & 1 \\
\hline Bangladesh & 1 & Greece & 2 & Paraguay & 1 \\
\hline Brazil & 2 & India & 12 & Spain & 1 \\
\hline United Kingdom & 7 & Italy & 3 & Serbia & 2 \\
\hline Bulgaria & 27 & Ireland & 2 & South Africa & 2 \\
\hline Kavkaz & 1 & Iraq & 2 & Slovenia & 4 \\
\hline China & 2 & Kazakhstan & 1 & Slovakia & 2 \\
\hline Canada & 2 & Kenia & 1 & Turkey & 6 \\
\hline Croatia & 1 & Pakistan & 3 & Uganda & 1 \\
\hline Czech Republic & 2 & Nigeria & 1 & Venezuela & 1 \\
\hline Netherlands & 1 & Norway & 1 & Total & 111 \\
\hline
\end{tabular}

Source: Image by the Author

A large number of the respondents (27 persons) come from Bulgaria, followed by India (12), UK (7) and Turkey (6). Representatives from Pakistan, Uganda, Argentina and Paraguay were also among the respondents.

The study searched for answers to questions related to the professional experience of the respondents in multicultural environment, as well as their interaction with representatives of different countries.

The data demonstrates unequivocally that a great majority of the respondent's regard culture as a competitive advantage (88.3\%) and an asset to the team, hence to the organization as a whole. What is of paramount importance to all stakeholders is the proper management of the latter, which is among the key challenges to the project manager. We also note the fact that $98 \%$ of the respondents had professional experience with people from other cultures, and $75 \%$ were working with members from different cultures at the time of the interview. This confirms the proper selection of respondents for this empirical study. An important fact too is that almost all respondents (96\%) find cultural awareness of paramount importance.

One should also note the fact that working in multicultural environment and managing a multicultural project team requires significantly more and more specific project management skills compared to the management of a culturally homogenous project team

Adequate multicultural team leadership is among the specific challenges to project managers and organisations trying to develop successful project teams in a multicultural environment.

The project manager is the main integrating resource for the formation and the functioning of the team. Additional challenges for him/her result from the integration of different 


\section{i[REMF}

communication models, behaviors, attitudes and approaches to each one of the members of the project team. In the conditions of multicultural teams, the project manager becomes a "mediator" between different worlds by overcoming cultural differences. Thus, we assume that the possible lack of encouragement of teamwork, of communication, adaptation and conscious attitude towards the needs of the team, are key factors affecting the project management.

Figure 1. The Funnel Model



Source: Image by the Author

Based on the key elements singled out in the study we have created a "Funnel Model" containing the necessary set of competencies the project manager needs for multicultural management:

* Communication

* Conscious attitude towards the needs of the team

* Adjustment/ Adaptation

- Fostering teamwork 


\section{i[CREMF}

$>$ Communication. Naturally, in this study, like other cross-cultural studies, communication is one of the key competencies needed by a project manager, regardless whether the project is traditional or of any other type. We regard communication a way to overcome uncertainty, and make reference to the fourth dimension of Geert Hofstede - uncertainty avoidance (Hofstede, 1991). In order to make communication effective and in line with this requirement, it has to be timely, originating from an appropriate source, correctly disseminated and managed (PMI, 2017). Communication is inseparably linked to the next manager competency - a conscious attitude to the needs of the team. Mostly when it serves for informing the team about cultural and personal differences for the purpose of avoiding misunderstanding.

Conscious attitude to the needs of the team. One of the first tasks of a project manager in a multicultural team is to become acquainted with the various cultures, their advantages and challenges, as well as to identify the cultural differences. The awareness about the cultural difference reduces the number of misunderstandings and improves the ability to communicate. Based on this, the next step is "adaptation of the developed communication strategy in the context of these differences "(PMBOK, 2017). Consciousness is regarded also from the point of view of the following elements, established by our study:

The combination of these elements (selection of the members of the project, professional skills) and the cultural sensitivity assist the project manager in planning communications based on cultural differences, which we deem a sufficient prerequisite for avoiding conflict. Inevitably, conflict resolution capacity, confidence building skills and achieving consensus are among the project manager skills.

$>$ Adjustment/Adaptation. Since each project is unique and not every process, tool or technique is applicable to all project, we arrived at the conclusion that a certain adjustment is needed of the latter in order to achieve the project goals. The project manager is the person who has the task of determining the right combination and of using the respective generally accepted good practices for each project. We deem that valid for the multicultural project environment too, from the point of view of adaptation of the culture of the participants in the project to the organisational and the newly formed project culture. We assume that, at a certain moment in time, such culture (own project culture) based on strong team values, would be entirely possible.

$>$ Fostering teamwork. Teamwork is of decisive importance for each project and is part of the last question of the survey of the mentioned criteria. Creating an environment for work, support and recognition for good results is also among the tasks of the manager. Cultural diversity in such environment sometimes leads to creating a "language of the team or a cultural norm that may differ from the home one"(PMBOK, 2017). The respect of the project manager for the multicultural principles creates an environment of mutual trust, clear and timely communication between the members and a cohesive 


\section{iEREMF}

team culture throughout the entire life cycle of the project. Further to the key competencies mentioned above, necessary for project management in multicultural environment, we suggest tools and mechanisms for practical application. The methods include but are not restricted to: team meetings; meetings with the immediate superior ("face to face"); team building exercises; shared portal (repository for sharing information); emails; etc.

The obtained results from the study confirm the established necessity to develop specific competencies of the project managers in multicultural project-oriented organisations, as well as specific steps for them to follow. Beyond doubt, technical competencies are of paramount importance for project managers, however, in addition to them, the so-called "soft" competencies/skills are becoming also this important.

\section{Conclusion}

A project manager is influenced by the multicultural environment as well as by his/her own national culture within which he/she has been socialized. His/her personal attitudes and stereotypes reflect on his/her style of management and have a decisive impact on the efficient management of the cultural diversity in the team. This is reflected to the greatest extent in the decision-making at various stages of project management, in the coordination of the tasks performed, in the leadership and authority, as well as in time management, project communication and project risk.

The management style of a project manager in a multicultural environment is characterized with a higher level of flexibility, timely reaction to problems arising, open dialogue, searching for consensus and compromise, as well as trying to avoid or mitigate conflict. Cultural diversity is one of the factors, which - in spite of adding value to the projects - may prove to be one of the greatest challenges in the practice of project management in a multicultural environment.

In view of the changes in the global business environment, new technology and cultural diversity, various skills and people have been brought together in the context of project management. The project manager is in charge of those aspects and his/her task is to make the best use of the factors of the environment, cultural differences included. A strong multicultural team is there when the creation of a strong inclusive culture and values is encouraged, when the project members are not only involved, but also empowered, which results in more productive teams and better performance.

With reference to the above, we can conclude that an important step was made for organisations in terms of implementation of projects in an international multicultural environment. And nowadays, in an unstable and controversial world, where there is little certainty and change is omnipresent, the need of a larger and richer set of tools, competencies, skills and techniques is greater than ever. 


\section{iEREMF}

\section{References}

[1] Alexandrova, M., (2016). Project portfolio management success: Preliminary results for evaluation of KPI in Bulgarian project-oriented organizations. Proceedings of the International Academic Conference on Management, Economics and Marketing, Czech Institute of Academic Education \& Czech Technical University, Prague, pp.117-125.

[2] Alexandrova, M. (2018). A principal component analysis of project portfolio management practices. Ekonomicko-manazerske spectrum, vol. 12 (2), pp. 96-105.

[3] de Carvalho, M.M. (2014). An investigation of the role of communication in IT projects. International Journal of Operations \& Production Management, vol. 34 (1), pp. 36-64.

[4] Chevrier, S., (2003). Cross-cultural management in multinational project groups. Journal of World Business 38, 141-149.

[5] Eberlein, M. (2008). Culture as a Critical Success Factor for Successful Global Project Management in Multi-National Service Projects. Journal of Information Technology Management, vol. XIX (3), pp. 27-42.

[6] Harzing, A., (2001). Of bears, bumble-bees, and spiders: The role of expatriates in controlling foreign subsidiaries. Journal of World Business, vol. 36 (4), pp. 366-379.

[7] Hofstede, G., (1991). Cultures and Organizations: Software of the Mind. London; New York: McGraw-Hill

[8] Kloppenborg, T. J., and Petrick, J. A. (1999). Leadership in project life cycle and team character development. Project ManagementJournal, vol. 30 (2), pp. 8-13.

[9] Mäkilouko, M. (2004). Coping with multicultural projects: The leadership styles of Finnish project managers. International Journal of Project Management, vol. 22(5), pp. 387-396.

[10] Marchewka, J.T. (2014). Information Technology Project Management. NY: John Wiley \& Sons.

[11] Muller, R., and Turner, R. (2010). Leadership Competency Profiles of Successful Project Managers. International Journal of Project Management, vol. 28, pp. 437-448.

[12] Picker, S., and Leker, J., (2009). Project Leadership Skills in Cooperative Projects. Management Research News, vol. 32 (5), pp. 458-468.

[13] PMI (2000). PMBoK: A Guide to the Project Management Body of Knowledge. Newtown Square, PE: Project Management Instute.

[14] PMI (2013). PMBoK: A Guide to the Project Management Body of Knowledge. Newtown Square, PE: Project Management Instute. 
$2^{\text {nd }}$ International Conference on Research in BUSINESS, MANAGEMENT and FINANCE $27-29 \mathrm{MARCH}, 2020 \quad$ OXFORD, UNITED KINGDOM

\section{iERPMF}

[15] PMI (2017). PMBoK: A Guide to the Project Management Body of Knowledge. Newtown Square, PE: Project Management Instute.

[16] Søderberg, A.-M. and Holden, N. (2002) Rethinking cross-cultural management in a globalizing business world. International Journal of Cross Cultural Management, vol.2 (1), pp.103-121. 